\title{
The painters behind the profile: the rise and functioning of communication departments in universities
}

\author{
Mari Elken $^{1}$ (D) Bjørn Stensaker ${ }^{1} \cdot$ Indra Dedze $^{2}$
}

Published online: 19 March 2018

(C) The Author(s) 2018

\begin{abstract}
It has been argued that universities are changing into becoming more professional as organizations, and this paper investigates this claim by exploring the emergence and tasks of communication departments in modern universities. Examination of universities in six Baltic and Nordic countries shows that communication departments are working closely with the institutional leadership and that communication is increasingly seen as a strategic function in the universities. This can position communication departments as a central internal coordinator between various organizational units and processes. While the findings indicate support for the assumption about more professional universities, those working within a communication department seem to have a broad and varied background and cannot be said to have developed a specific professional identity in all the institutions. However, our findings do indicate increasing contact and close relations between communication specialists across university borders which may result in a stronger professional identity over time.
\end{abstract}

Keywords Communication - Organization - Organizational change P Professionalization · Higher education · Strategy

Mari Elken

mari.elken@nifu.no

Bjørn Stensaker

bjorn.stensaker@iped.uio.no

Indra Dedze

indra.dedze@lanet.lv

1 Nordic Institute for Studies in Innovation, Research and Education (NIFU), PO box 2815, Tøyen, 0608 Oslo, Norway

2 University of Latvia, 19 Raina Blvd., Riga LV-1586, Latvia 


\section{Introduction}

Universities are increasingly under pressure to act as strategic knowledge organizations. While the role of leadership in strategic planning has been highlighted already in some of the more classic works (Kotler and Murphy 1981), the proliferation of benchmarks, rankings, and branding as means for positioning universities has been strengthened considerably in recent years (Kehm and Stensaker 2009). It is increasingly taken for granted that university performance is measured according to such dimensions as universities are expected to perform both on the national and the international arena. This development has also created new demands for university administration, where this task is increasingly placed in specialized communication departments (Kirp 2003).

There is an emerging literature on university branding, marketing, and reputation management as a process (see, e.g., Christensen and Gornitzka 2016; Drori et al. 2013; Stensaker 2007; Williams and Omar 2014; Chapleo 2010; Wæraas and Solbakk 2009), the way it impacts student choice (Royo-Vela and Hünermund 2016), and the challenges of marketing in higher education context (Sands and Smith 2000). Marketing in higher education has in itself become an established area for research in recent decades (Hemsley-Brown and Oplatka 2006). At the same time, there is surprisingly little research on the actors and units that are central in the branding and marketing processes - the communication departments. From an organizational starting point, communication departments are particularly interesting as they can be seen as the mediators between the universities and their environments (Cornelissen 2014). Nevertheless, there is limited knowledge about how communication departments as specific organizational units operate within higher education institutions. As such, our interest in the current article lies in the operation of such units- how they operate and how they are integrated into the fabric of universities. However, our point of departure is that the current operations of these units are closely related to their transformation from information to communication units (Kirp 2003). Drawing on literature on organizational studies, we argue that the establishment and expansion of such departments can both be seen as a form of professionalization process within organizations, as well as a way for organizations to confirm with expectations of "good organization." The underlying logic for establishment of these departments can thus be functional or symbolic, and their tasks can be more or less focused on communication field as a specific profession.

The article explores the establishment and tasks of communication departments in 13 research intensive universities in the Nordic and Baltic countries. While these two regions have a range of historical and cultural differences, they have both been exposed to a range of external expectations. These external pressures emphasize the necessity to address external positioning and profile. The institutions we have studied have traditionally had a rather well-established position in the region, being considered among the leading institutions. This means that they have had a market position where they do not need to "market" themselves very much. This highlights how universities in the Nordic and Baltic region can be particularly relevant for examining the establishment and operation of communications departments as new organizational units; unlike American or British universities where focus on branding and professional communication has been a more established practice over several decades, this is still a rather novel approach in these countries. This starting point is linked to the nature of higher education systems, where marketization and commercialization of universities have historically been less prominent. 
The next section will focus on our analytical framework, with particular focus on organizational change and integration of new professions to university organization. After this, the case selection and methodological approach will be presented, followed by a discussion of the empirical cases.

\section{Unpacking the development of new administrative organizational units in higher education}

The establishment of communication departments in universities can be perceived as a way to manage the relationship between the university and its environment (Cornelissen 2014). This responsibility may be quite challenging due to the complexity relating to the internal organization and characteristics of universities, and the fragmented environment surrounding these organizations (Pinar et al. 2011; Sands and Smith 2000).

Historically, most universities historically have had some units that have had the responsibility for providing information to the outside society (Molesworth et al. 2010). However, due to organizational growth and increased specialization of administrative tasks, university administration has become more professional in the past decades (Gornitzka and Larsen 2004). Where initial studies on university organization had the tendency to use a residual category for all non-academic staff, more nuanced categorizations have been developed for university administration-distinguishing them from technical staff and further making a distinction between clerical and professional staff within administration (Gornitzka and Larsen 2004). This reflects the multitude of new professions that have entered the university, often referred to as the "rise of the management profession" within universities (Krücken and Meier 2006, pp. 251-252).

This professionalization implies that university administration becomes increasingly specialized due to the kinds of tasks they engage in. There is an underlying functional logic, as these organizational units manage specific tasks in the organization-whether this concerns delivering data to rankings, managing PR issues, or communicating to prospective students at a more competitive marketplace. The case of communication departments could be seen as one example alongside several others, the establishment of departments in accounting, research management, and HR. While the label "communication" does not necessarily imply "new" practices (Gioia and Thomas 1996), one could expect that a result of increased professionalization could have organizational consequences for the university. For example, a communication department with a highly professionalized staff may potentially create organizational inconsistency in that a strong internal professional ethos may lead to tensions between the aims and objectives of the communication department and other departments (Meyer and Rowan 1977). The existence of a strong communication profession may also create pressure for isomorphism with other professionals outside the university; the development of professional standards (Czarniavska and Mazza 2013) as a way to legitimate their occupational autonomy (DiMaggio and Powell 1983, Powell 1991). This, in turn, could also further emphasize the tensions between communication professionals and other staff within the university.

Yet, one can argue that the establishment of new organizational administrative units would not in all instances be a result of professionalization process. Compliance with environmental demands can also be linked to normative and cultural expectations to secure legitimacy and acceptance (Drori et al. 2013). For universities, this relate to situations where the society expects them to become more "complete" and "real" organizations (Christensen and Gornitzka 
2016; Krücken and Meier 2006; Maassen et al. 2012); in order to signal these characteristics, special organizational units, such as communication departments, would be developed as a means to fulfill specific expectations. Establishment in such instances is not primarily a functional need due to specific tasks, but symbolic action to signal particular status. Earlier research has shown that universities may emulate other universities as a result of changing external conditions but also due to uncertainty about the appropriate strategic action (Labianca et al. 2001). Thus, a possible outcome is structural and organizational imitation of those universities seen as successful in the environment (DiMaggio and Powell 1983). In this instance, organizations are more concerned about "ceremonial conformity" as a source for legitimacy (Meyer and Rowan 1977), a form of symbolic rather than functional logic. In such instance, one can expect that the tasks for the communication department would not be clear, and they may remain decoupled from the remaining of the organization.

The two arguments thus represent a continuum, where one emphasizes the professional and functional logic, the other emphasizes a symbolic one. Both provide explanations for why such units are established as well as their links to the remaining of the organization. One could expect that the more professionalized such unit is, that is, the more such units are marked by communications professionals who also have external attachments to the communications field; the more tension one can expect between the communication department and the faculties and other departments. As branding and marketing exercises may be met with resistance and skepticism in many universities (Stensaker 2007), it can be expected that while they may have closer links with the institutional leadership (Wæraas and Solbakk 2009) in handling the relationship to the environment, their integration with the remaining of the organization would be marked by tension.

\section{Methodological approach}

\section{Empirical setting and case selection}

Analysis of branding and marketing in higher education has often focused on the research-intensive universities in countries that tended to be front-runner in the increasing marketization of higher education, i.e., the USA, the UK, Australia, and New Zealand (Molesworth et al. 2010). Less is known about how branding and marketing takes place and is organized in other countries and regions. The empirical context for the current article is the Nordic and the Baltic region. While the Nordic region increasingly is seen as also encompassing the Baltic countries, it can be argued that the Baltic countries do have a different history and different characteristics, not least due to the inclusion of these countries in the former Soviet Union.

The Nordic region is characterized by the Nordic welfare state model, also having specific ideas of the role of higher education in society. While reform agendas in recent decades suggest somewhat different trajectories (Christensen et al. 2014), the countries have all recently experienced that the emphasis on excellence has become more pronounced (Vabø and Aamodt 2009). Viewed from the outside, the region can nevertheless be seen as relatively cohesive and stable over time since the Second World War. As our analysis only includes three of the Nordic countries, these are also countries that share a number of historical similarities. The historical development of the three Baltic states during the last hundred years is quite similar. In 1918, the independent countries of Estonia, Latvia, and Lithuania were established that was characterized by a rapid 
development of the respective national education systems including higher education institutions. As of 1940 until 1991, all three countries were part of the Soviet Union. During 50 years of the Soviet Rule, the national education systems were transformed and made uniform suitable for socialist regime. In 1991, the Baltic States regained independence, and in 2004 became members of the European Union as well as become fully fledged countries of European Higher Education Area (Dedze and Rubene 2016; Saar and Roosalu in print; Leišytė et al. in print). The Baltic countries are striving to build a democratic society and become recognized and competitive members of the Western society. In terms of environmental conditions, the universities are meeting a considerably more turbulent environment. Thus, one could also expect that there would be a different trajectory of internal reorganization and the demands from the environment, with a less stable environment, more frequent internal reorganization processes, and higher degrees of aiming to emulate successful institutions from abroad. The expectation is that this would imply that the communications departments obtain a somewhat different role than in the case of the Nordics, where the institutional environment is more stable.

In the current study, 13 universities from six countries in these two regions are examined: The University of Copenhagen, Århus University, Denmark Technical University, University of Oslo, Norwegian University of Science and Technology (NTNU), University of Bergen, The Royal Technical University in Stockholm, and Uppsala University from the Nordic region, and Riga Technical University, University of Latvia, Vilnius University, Kaunas University of Technology, and Tallinn University of Technology from the Baltic region. All of the universities can be said to be quite established and prestigious institutions, and the sample include some of the oldest, largest, and best performing universities in the region. The size of the institutions varied somewhat, where universities in Århus, Copenhagen, and Uppsala as well as NTNU have approximately 40,000 students, while the Baltic universities have about 10-20,000 students. However, all of the institutions can still be considered as large institutions in the respective higher education systems.

While potentially worse-performing institutions could be expected to be more dependent on actively attempting to shape their image in a performance-oriented environment (Bakewell and Gibson-Sweet 1998), the current sample could be expected to have a more ambiguous position with respect to the development of communication department. These institutions can be seen as so established within their countries that their need to strengthen external branding and marketing would be limited, and that their history and organizational identity would imply considerably internal resistance towards any ideas related to branding, marketing, and external profiling (Chapleo 2010). Therefore, they comprise an interesting case for a "need" to develop communication departments and to investigate their functions more in detail. From a theoretical starting point, one can presume that the organizational context for these departments can be seen as least likely in these institutions. Old research-intensive universities tend to be highly institutionalized organizations, with high self-esteem and high academic ideals. Consequently, one could expect that the possible clash of norms and values could be most visible when a 'communication agenda' is introduced to the organization. However, given their unique national position, one could also expect that these institutions might want to expand their brand and strengthen their position further, not least internationally. At the same time, they are all located in regions which are in somewhat peripheral regions of Europe, with the Baltic region being the more peripheral of the two regions. 


\section{Data and methods}

The analysis in this article is based on interviews with representatives of these departments, and through review of organizational maps and documents in which the positioning of the departments in the organizational structure. Interviews were primarily conducted in the form of a written e-mail exchange and in one case as a phone interview. We contacted the leader of the departments, assumed to have the best oversight of the department. In most cases, it was the contacted person who also provided the answers; in some cases, the inquiry was forwarded within the department. We initially contacted 18 institutions, 3 in each country, whereas, we acquired responses from 13 institutions. Questions regarded the history and organization of the communications department, what they perceived as their most important tasks, and what they considered as most typical tasks and spend most time on. Furthermore, questions concerned their evaluation of their professional autonomy and their role in strategic work at the university. The departments also reported on the profile of their employees (professional and educational background in broad terms) and engagement with other communication departments in higher education as well as engagement in networks of the communication profession. Finally, they provided information about what they considered as key challenges regarding working in universities.

This data collection has, of course, limitations. The responses are based on self-reported data from one key respondent within the institution. At the same time, questions were as much as possible formulated in a factual manner where respondents would report on what they "do." It should be noted that the analysis has clear limitations in terms of generalizability and should be seen as a first attempt to explore the role and function of communication departments in modern universities from an organizational perspective. Despite these limitations, the data also showed that a range of rather clear patterns emerged. We present the main reflections in two separate sections, first regarding establishment of the units in these universities, then with focus on their organizational functions.

\section{Communications departments: establishment and tasks}

In this section, the empirical results from the study are presented, following the two dimensions from the analytical framework. Emergence of the units examines when these units have been established, including their basic characteristics. The latter includes the professional profile of their staff, internal structure, and recent processes of reorganization. In the discussion of their tasks, their tasks and roles in the organization are discussed, also examining their integration to the organization as a whole.

\section{Establishment and structure}

All the selected universities have a separate communication department centrally within the university administration, and a key characteristic of all the departments is that they have during the last decade been exposed to several reorganizations. Apart from two, these units have "communication" in their title. All the departments in the Nordic universities have a relatively long history at the universities, although the current "communication" label seems to have been added during the 2000s. Prior to this, they were either an information unit or part of a larger administrative unit in the central administration. In the Baltic institutions, most of the 
institutions had the communication label in the title. However, two of the institutions instead have a unit for public relations and marketing, as there had been a "competitive, marketing-driven change in the university sector" in the country. Furthermore, Baltic universities note a higher number of reorganization processes, which can be seen as natural considering the scope of overall changes in transition countries and the higher education sector.

While there is some variation in overall institutional size and we lack systematic data on how the number of staff has developed over time, the data collected shows that these departments have reached a substantial size in the number of employees. The average size of communication departments is between 25 and 30 persons in our sample of Nordic universities (one institution reported 40 employees) and between 10 and 18 in the Baltic ones. Furthermore, some universities also have de-centralized communication officers within faculties and schools. Hence, the actual number of people working with communication issues within the selected universities may be considerably larger. This indicates that communication task in these institutions has become an established and specialized function and unit.

Regarding staff profile, Nordic and Baltic region have some differences in what is being reported as a typical background. In both regions, there is reporting of people with journalist and communications background. In the Nordic case, the responses indicate that it is common to have backgrounds in communications and journalism, but several of the respondents also emphasize that the departments also include a range of people who have other kinds of humanistic or social science education and who also have experience with university administration in general. This is also linked to the internal structure of the departments and the kinds of sub-units that exist. Baltic institutions report to a higher degree that they only consist of specific communication and journalism backgrounds - as all of the institutions highlight that staff professional background is in communication or journalism, and to a lesser degree, have their expertise building on internal organizational experience or other social science fields.

One possible explanation for this can also be found in the labor market context in the two countries, where Baltic countries experience overproduction of the communication specialists; thus, they are more available on the labor market, and higher education institutions can easily attract those specialists. This happened because after the collapse of the Soviet Union and greater accessibility of private higher education, social sciences become rather popular field of studies both due to the greater interest of students to choose these subjects as oppose to natural sciences and those programs were cheaper to develop and offer for private higher education institutions. In the Nordic context, universities have been operating under much more stable conditions, including the labor market.

Despite somewhat different professional profiles, there is similarity in their description of their professional autonomy:

"...each of the people is responsible for their work and we expect considerable independence, knowledge of their field and a proactive approach." (Baltic)

"Everyone in the department have professional autonomy to decide which the best way to achieve a goal are." (Baltic)

"As long as we follow up on the strategy of the institution, we have freedom to choose how we want to fulfil those tasks." (Nordic)

"When we conduct our tasks we usually have much autonomy, as we often have an advisory role and less often take a role where we are told to 'do this and do that.' The way we organize our tasks is also very independent." (Nordic) 
This, however, should also be interpreted with caution, given that the responses are based in a key respondent answer and not on individual interviews with a large segment of the staff.

Structurally, these units are most often functionally divided between various tasks. As communication infrastructure is developing rapidly due to technological advancements, most of the communication departments have separate units for web-based information, development of information and branding material (logos, design schemes, etc.), and rapid responses to public media. Two areas emerge where the departments appear to be rather different. One of these is media and video, where some universities have in this unit also staff which are experts on video and media that can produce quite professional products in this area. Another such task is research communication. In some of the institutions, this is placed at the central communications department, also as this task is poorly embedded in other administrative units:

"communication with the society is the fourth task of the university, but at the same time this is an area that no other administrative unit takes ownership of." (Nordic)

However, in several of the institutions, this is also decentralized to individual faculty-level units, where communication departments centrally engage in coordination processes.

The fact that many communication departments have been exposed to reorganizations during the last decade is often explained with changing views on the role of the communication department in the institutional leadership. Thus, the position of the communication departments within the organizational structure can be characterized as somewhat unstable. Whether the communication departments will continue to be characterized by personnel, diversity and varied experiences are not clear. All of the departments analyzed report that they are quite frequently engaged in national and international networks, and they acknowledge that these arenas are important for acquiring new ideas and practices. All of the communication departments also admit that they are close followers of what other universities are doing in their communication efforts and that there is much interest to strengthen their expertise by looking at others. This suggests that despite some instability in terms of their structure and min profile, communication is becoming established in universities with a distinct professional identity and a part of a wider organizational field within communication. Moreover, the kinds of activities they engage in are also inherently part of following what other institutions do.

\section{Tasks and functions}

Regarding their tasks and function in the organization, all the units studied describe a wide variety of tasks that are considered important. Rather obviously, student recruitment is an important task, and a number of them also explicitly emphasize their role in brand management in this respect. However, managing press coverage also means that the units engage in "crisis management." For example, one of the institutions emphasizes how things end up in their unit the moment they become "problematic" for the institution as a whole. The extent to which something is considered high on the agenda is at least to some extent also driven by the environment, evident in the description of time allocation by one of the respondents:

"The allocation of time is difficult to estimate; it depends on the situation that is in turn

influenced by external conditions." (Nordic) 
They work closely with the institutional management and leadership and that their tasks are closely linked to the strategy of the institutions. The respondents in all institutions report high level of contact and frequent meetings with leadership. They report that contributing to strategic work at the university is important and rather an essential aspect of their activities:

"We also contribute to finding solutions to the major cross-cutting tasks that have an aim to strengthen the university's core functions of supporting research and education. I am for example in a coordinating committee that works with internationalization and development of the university's strategic partnerships." (Nordic)

At the same time, this view does not imply that the units act on their own; these contributions are embedded in wider organizational strategies, as the previous respondent continued:

"We do not speak so much about strategies and we do not have an overarching communications strategy. Instead we strategically support the leadership in their strategic processes of solving key issues in the organization." (Nordic)

In some universities, communication has become an important strategic issue, and new advisory bodies have been developed involving key decision-makers within the university, where the communication department set the agenda and is expected to implement the actions decided upon. However, several of the units also report shifting priorities and unstable emphasis. Within this group of universities, it seems that the leadership over time has had quite different expectations concerning what a communication department should do, and the place this unit should have in the organization.

In most of the responses, organizational accountability was emphasized, in both regions. Their operation is seen in context of strategic development of the institution and in light of their tight linkage to central leadership. This was exemplified in most of the responses, and when asked about the autonomy of the department in how they conduct their tasks, one respondent even questioned the whole notion of autonomy in this context:

"Autonomy, yes. We are not a newspaper, this is rather obvious. (..) We have a support function, so I am not sure if autonomy is the right word here." (Nordic)

"We set our goals based on the strategic plans of the institution, and coordinate with the rectorate in this. We are rather autonomous, but we have accountability for the results." (Baltic)

However, while they work with leadership, their organizational function is not unquestioned among academic staff, suggesting that some decoupling can be identified:

"there is internal opposition to branding as this has too commercial associations and because staff identity is closely linked to their discipline, while it is usually the whole university that is being branded (for competitive reasons), whether it is businesses, the state or the EU (e.g. Horizon)." (Nordic)

A number of other respondents also emphasize that it is not always easy to integrate the administrative and academic logic in their work, and one notes that they are specific deliveries, rather than strategies that actually win "respect" among academic staff.

While we envisioned communication departments as primarily externally oriented units, the data also shows a second important dimension which is much more internally oriented. An 
important characteristic is that they also are very much involved in internal communication processes directed at students and academic and administrative staff. There are somewhat divergent views on how diversity should be managed within universities. While some of those who were interviewed emphasized the problematic nature of the university as an organization and the problems that emerge when they try to identify and agree on a unified message to provide to the surroundings, others expressed more understanding for the historic nature of the university and the importance of values such as academic freedom. While the first category tends to emphasize the need of the society to be informed about university affairs, and that the "third mission" of the university, i.e., the responsibility to bring useful and relevant information on research findings to the public, should be given high priority, the second category signal that concepts such as "university democracy" also is important for those working with communication.

"the university as an academic organization sets high value on academic freedom. Academic staff in general have well-established positions and esteem and they are used to a high degree of autonomy. Our challenge is to generate and consolidate shared values and identity and creating a sense of belonging." (Baltic)

"It is the nature of universities is that we do not have a tight control of communication: university rarely speaks with only one voice. It's something that can make communications work harder, but academic freedom and university democracy are an important core value for us!" (Nordic)

In this context of diversity, this internal function can thus obtain a mediating role, not least when communication function can also enable additional lines of coordination within universities. In some of the universities analyzed, the communication department had taken on a role as a "coordinator" between various departments concerning more administrative issues such as the development of the annual actions plans, to establish systems for data gathering and systematization, and performance indicators. In this way, the communication department can be said to be involved in issues beyond "communication" with the environment and obtain a significant organizational function as internal mediators and coordinators. This kind of function can have an important function for the organization as a whole in managing internal consistency.

\section{Discussion and concluding remarks}

We positioned this paper in the recent literature on how universities are changing as organizations, and the tendency towards greater professionalization and specialization of administrative tasks and responsibilities in the modern university.

The starting point in the article was that communication departments for universities in these two regions had comparatively been less in focus than in systems that have had for a longer time had a clear emphasis on student markets. However, in both of these regions, one can also identify an emerging field of communication in higher education. The empirical findings from the article suggest that, at least with respect to formal structures, universities are building up more comprehensive and larger communication departments at central level, although the staffing of these units seems to be more diverse. Differences between the two regions were most evident in terms of staff profile. Moreover, the two regions also show important similarities in how communication departments function. The commonalities can be 
seen as a basis to argue for possible general analytical insights about the role of communication departments in modern higher education landscape. These findings also echo the wider organizational rationalization processes taking place in higher education (Krücken and Meier 2006).

The rather similar timing of when communication departments were established in the selected universities suggests that there may also be more normative and cultural explanations related to this development, echoing similar development in private sector organizations (Cornelissen 2014). There are consistent narratives found about how the daily life of communication departments is about responding and reacting to external requests for information from a range of different stakeholders, and the range of tasks they engage in. While it seems that some of these units are in a somewhat precarious situation and dependent on leadership priorities, it also appears that the function has obtained a spot in university administration and they work closely with university leadership in strategic processes.

While the institutions also show some diversity in terms of staff composition, there are indications that communication is becoming professionalized within universities. Many of these communication departments seem to pay considerable attention to what other universities are doing and that they tend to benchmark themselves towards institutions they consider similar. This is not unique for this sample of institutions (see also Labianca et al. 2001), and also, this supports research that has studied the role of rankings in the Nordic region (Elken et al. 2016). Hence, the "environment" these institutions enact to seems to be quite dominated by their peer institutions. The fact that those working in such departments also have established their own professional arenas and networks further indicate that the mechanisms for such normative and cultural exchange of ideas certainly are present and possible in the process of being institutionalized. One can question what the consequences of this can be in the long run. Here, distinct profiles emerged in terms of staff profile - and whether staff was recruited from the outside as communication professionals, or whether these had been earlier administrative employees who had obtained new tasks. One could argue that communication departments that have a thorough experience with and a deep understanding of the identity and culture of a given university may be in a better position to be integrated into university affairs that a department consisting of communication professionals with only private sector background and limited experience in the sector. However, the data here was at this point too limited to explore the specific consequences of these two profiles.

However, while the analytical perspectives outlined different possible functions, an alternative internal function emerged from the data. This form focused both on being a service to the leadership, while at the same time having a more networked function in terms of internal communication. The fact that these departments have an important "service function" to the institutional leadership could largely be expected. From a more corporate communication and reputation management perspective, this task is normally expected as being central to these types of units (Cornelissen 2014). Still, based on our data from the representatives and leaders of the communication departments, a considerable amount of their attention is allocated to what we might term as "internal communication" within the university. In such instances, communication departments seem to take on a role as mediators between the institutional leadership and the often complex and quite fragmented heartland of the university. This function might be a reflection of the institutional characteristics of the universities studied, as comprehensive and large universities are over-represented in our sample, and because the "brands" of these universities are quite established within the Nordic region (Christensen and Gornitzka 2016), having the potential consequence that the institutions do not prioritize 
external branding and marketing activities to the same degree as their US and UK counterparts (see also Elken et al. 2016). Nevertheless, the weight given to and the amount of time and energy devoted to internal coordination stand in contrast to the external functions one would expect dominated the agenda of these departments (Cornelissen 2014). This might imply quite different functions of communication departments in universities than in other organizations engaging in corporate communication activities.

With relatively weak hierarchical decision-making structures in place, communication departments may thus conduct a very important "service function" to the institutional leadership that of coordination and making a fragmented organization more coherent. By engaging in common setting of standards, and internal communications, they can contribute to mitigation of some of the organizational fragmentation modern universities face. Having a key role to play in such coordination activities could be an explanation for what we have found as an "expanding" role of communication departments as coordinators of internal administrative processes that sometimes go way beyond traditional tasks of those working with communication. Yet, one could argue that this function is also dependent on the ability of these departments to actually take this mediating role. This gives reason to argue that communications as a profession within universities obtain a distinct professional profile. In particular for the Nordic institutions, we have little evidence that communication departments only consist of "communication professionals." While staff with such competence indeed is found in these units, it seems that the area of communication can be seen as an example of an "educational circle" where professions taught within the university reenter the organization (Czarniawska and Mazza 2013). This is not a novel phenomenon as universities have a tradition for hiring administrative staff with an educational background from their own institutions (Gornitzka and Larsen 2004). To take the role as organizational mediators, this experience may make those working in communication departments well-equipped with a broad understanding of the university. At the same time, the data also suggests that professional dynamics are also dependent on the wider societal developments, and considerable societal upheaval can challenge such patterns (as was the case with the economic crisis in the Baltic region).

More importantly, the findings in this study also show that the analysis of rationalization and modernization of universities also need to take into account the dynamics of the new professions that have entered the university in a "service function." Rather than only viewing them as an indicator of wider change processes, a more detailed analysis of such units is warranted. This is particularly the case given the diverse organizational functions that such units can take, adding new layers of links beyond traditional administrative and academic lines of authority in universities.

Our conclusion, based on the sample of institutions investigated in this paper, is that the new communication departments found in major universities in the Nordic and Baltic regions are not only focused on painting a distinct external profile but in a number of institutions also have an important role of being a new layer of internal organizational coordination within the university. As large comprehensive universities are organizations with multilayered and quite complex relationships with their environment, relationships that often bypass the communication department altogether, it is perhaps understandable that the current focus on internal coordination is a way for the institutional leadership to try to influence image and the profile being developed. As such, the functions of the communication departments may be more indirect, as a way to foster a more unified message being conveyed to the environment. 
Funding The study has received funding from Norway Grants Programme 2009-2014 in accordance with the project: "EU policies impact to the transformations of the higher education and research system in Norway and Latvia" agreement no. NFI/R/2014/006.

Open Access This article is distributed under the terms of the Creative Commons Attribution 4.0 International License (http://creativecommons.org/licenses/by/4.0/), which permits unrestricted use, distribution, and reproduction in any medium, provided you give appropriate credit to the original author(s) and the source, provide a link to the Creative Commons license, and indicate if changes were made.

\section{References}

Bakewell, C. J., \& Gibson-Sweet, M. F. (1998). Strategic marketing in a changing environment-are the new UK universities in danger of being "stuck in the middle"? International Journal of Educational Management, 12 (3), 108-113.

Chapleo, C. (2010). What defines "successful" university brands? International Journal of Public Sector Management, 23(2), 169-183.

Christensen, T., \& Gornitzka, A. (2016). Reputation management in complex environments - a comparative study of university organizations. Higher Education Policy, 1-18.

Christensen, T., Gornitzka, Å., \& Maassen, P. (2014). Global pressures and national cultures: a Nordic university template. In P. Mattei (Ed.), University adaptation in difficult economic times (pp. 30-51). Ocford: Oxford University Press.

Cornelissen, J. (2014). Corporate communication: a guide to theory and practice. London: Sage.

Czarniawska, B., \& Mazza, C. (2013). Consulting university: a reflection from inside. Financial Accountability \& Management, 29(2).

Dedze, I., \& Rubene, Z. (2016). Universities in Latvia - from the Soviet to European higher education area. Foro de Educación, 14(21), 13-38.

DiMaggio, P. J., \& Powell, W. W. (1983). The iron cage revisited. Institutional isomorphism and collective rationality in organizational fields. American Sociological Review, 48, 147-160.

Drori, G. S., Delmestri, G., \& Oberg, A. (2013). Branding the university: relational strategy of identity construction in a competitive field. In L. Engwall \& P. Scott (Eds.), Trust in higher education institutions (pp. 134-147). London: Portlandd Press.

Elken, M., Hovdhaugen, E., \& Stensaker, B. (2016). Global rankings in the Nordic region: challenging the identity of research-intensive universities? Higher Education, 1-15.

Gioia, D. A., \& Thomas, J. B. (1996). Identity, image and issue interpretation: sensemaking during strategic change in academia. Administrative Science Quarterly, 41, 370-403.

Gornitzka, Å., \& Larsen, I. (2004). Towards professionalisation? Restructuring of administrative work force in universities. Higher Education, 47(4), 455-471.

Hemsley-Brown, J., \& Oplatka, I. (2006). Universities in a competitive global marketplace: a systematic review of the literature on higher education marketing. International Journal of Public Sector Management, 19(4), 316-338.

Kehm, B. M., \& Stensaker, B. (Eds.). (2009). University rankings, diversity, and the new landscape of higher education (Vol. 18). Rotterdam: Sense Publishers.

Kirp, D. L. (2003). Shakespeare, Einstein, and the Bottom Line. The marketing of higher education. Cambridge: Harvard University Press.

Kotler, P., \& Murphy, P. E. (1981). Strategic planning for higher education. The Journal of Higher Education, 52 (5), 470-489.

Krücken, G., \& Meier, F. (2006). Turning the university into an organizational actor. In G. S. Drori, J. W. Meyer, \& H. Hwang (Eds.), Globalization and organization: world society and organizational change. Oxford: Oxford University Press.

Labianca, G., Fairbank, J. F., Thomas, J. B., Gioia, D. A., \& Umphress, E. E. (2001). Emulation in academia: balancing structure and identity. Organization Science, 12(3), 312-330.

Leišyte, L., Rose, A.-L., Schimmelpfennig E. (in Print). Lithuanian higher education: between path-dependency and change. In: J. Huisman, A. Smolentseva, I. Frumin (Eds.) 25 Years of Transformations of Higher Education Systems in Post-Soviet Countries: Reform and Continuity. Palgrave.

Maassen, P., Nerland, M., Stensaker, B., Vabø, A., \& Vukasovic, M. (2012). Change dynamics and higher education reform: effects on education, research, governance and academic profession. In M. Vukasovic, P. 
Maassen, M. Nerland, B. Stensaker, \& A. Vabø (Eds.), Effects of higher education reforms: change dynamics: change dynamics (pp. 1-20). Rotterdam: Sense Publishers.

Meyer, J. W., \& Rowan, B. (1977). Institutional organizations: formal structure as myth and ceremony. American Journal of Sociology, 83, 340-363.

Molesworth, M., Scullion, R., \& Nixon, E. (2010). The marketisation of higher education: Routledge.

Pinar, M., Trapp, P., Girard, T., \& Boyt, T. E. (2011). Utilizing the brand ecosystem framework in designing branding strategies for higher education. International Journal of Educational Management, 25(7), 724 739.

Powell, W. W. (1991). Expanding the scope of institutional analysis. In W. W. Powell \& P. J. DiMaggio (Eds.), The new instituionalism in organizational analysis (pp. 183-203). Chicago: University of Chicago Press.

Royo-Vela, M., \& Hünermund, U. (2016). Effects of inbound marketing communications on HEIs' brand equity: the mediating role of the student's decision-making process. An exploratory research. Journal of Marketing for Higher Education, 26(2), 143-167.

Saar, E., Roosalu T., (in Print). Estonia: post-socialist liberalism and post-postsocialist consolidation. In: J. Huisman, A. Smolentseva, I. Frumin (Eds.) 25 Years of Transformations of Higher Education Systems in Post-Soviet Countries: Reform and Continuity. Palgrave.

Sands, G. C., \& Smith, R. J. (2000). Organizing for effective marketing communications in higher education: restructuring for your competitive edge in marketing. Journal of Marketing for Higher Education, 9(2), 4158.

Stensaker, B. (2007). The relationship between branding and organisational change. Higher Education Management and Policy, 19(1), 1-17.

Vabø, A., \& Aamodt, P. O. (2009). Nordic higher education in transition. In D. Palfreyman \& T. Tapper (Eds.), Structuring mass higher education. The role of elite institutions (pp. 57-72). Abingdon: Routledge.

Wæraas, A., \& Solbakk, M. (2009). Defining the essence of a university: lessons from higher education branding. Higher Education, 57(4), 449-462.

Williams, R. L., \& Omar, M. (2014). How branding process activities impact brand equity within higher education institutions. Journal of Marketing for Higher Education, 24(1), 1-10. 